\title{
Incidência do míldio em cebola sob adubação mineral e orgânica
}

\author{
Paulo Antônio de S. Gonçalves ${ }^{1}$; Carlos Roberto Sousa e Silva ${ }^{2}$; Pedro Boff ${ }^{1}$ \\ ${ }^{1}$ Epagri, EE Ituporanga, C. Postal 121, 88400-000 Ituporanga-SC; E-mail: pasg@epagri.rct-sc.br; ${ }^{2}$ UFSCar, Depto. Ecologia e Biologia \\ Evolutiva, C. Postal 676, 13565-905 São Carlos-SP; E-mail: dcrs@ power.ufscar.br
}

\section{RESUMO}

Analisou-se a relação entre adubação mineral e orgânica sobre a incidência de míldio (Peronospora destructor) em cebola (Allium сера). O trabalho constituiu-se de dois experimentos localizados em Ituporanga, conduzidos entre agosto e dezembro de 1998. O experimento 1, com fontes orgânicas, constou dos tratamentos: esterco de suínos, esterco de aves, composto, esterco de peru e húmus, na dosagem de $75 \mathrm{~kg} / \mathrm{ha}$ de $\mathrm{N}$; esterco de suínos, na dosagem de $37,5 \mathrm{~kg} /$ ha de N; adubação mineral, 30-120-60 kg/ha de N-P $\mathrm{O}_{5}-\mathrm{K}_{2} \mathrm{O}$; 60$240-120 \mathrm{~kg} / \mathrm{ha}$ de $\mathrm{N}-\mathrm{P}_{2} \mathrm{O}_{5}-\mathrm{K}_{2} \mathrm{O}$ e testemunha sem adubação. O experimento 2 constou dos tratamentos: fontes minerais, 30-120-60 kg/ ha de N-P $\mathrm{O}_{5}-\mathrm{K}_{2} \mathrm{O} ; 90-360-180 \mathrm{~kg} / \mathrm{ha}$ de N-P $\mathrm{O}_{5}-\mathrm{K}_{2} \mathrm{O} ; 75 \mathrm{~kg} / \mathrm{ha} \mathrm{de}$ $\mathrm{N} ; 225 \mathrm{~kg} / \mathrm{ha} \mathrm{de} \mathrm{N} ; 80 \mathrm{~kg} / \mathrm{ha} \mathrm{de} \mathrm{P}_{2} \mathrm{O}_{5} ; 240 \mathrm{~kg} / \mathrm{ha} \mathrm{de} \mathrm{P}_{2} \mathrm{O}_{5} ; 60 \mathrm{~kg} / \mathrm{ha} \mathrm{de}$ $\mathrm{K}_{2} \mathrm{O} ; 180 \mathrm{~kg} / \mathrm{ha}$ de $\mathrm{K}_{2} \mathrm{O}$; esterco de suínos + fosfato natural, em três combinações, 7,9+0,1, 15,7+0,2 e 47,2+0,6 t/ha, respectivamente; testemunha sem adubação. Não houve diferença entre as fontes mineral e orgânica sobre a incidência de míldio. A relação entre nutrientes e doença foi variável entre datas de amostragem e distinta para fontes minerais e orgânicas.

Palavras-chave: Allium cepa, Peronospora destructor, nutriente, agricultura orgânica, agroecologia.

\begin{abstract}
Incidence of downy mildew in onion growing under mineral and organic fertilization

The incidence of downy mildew, Peronospora destructor Berk. Casp., in onion growing in chemical and organic fertilized plots was evaluated in Ituporanga, Santa Catarina State, Brazil. Two experiments were carried out between August to December 1998. The treatments in the first experiment with organic sources were: $75.0 \mathrm{~kg} / \mathrm{ha}$ of $\mathrm{N}$ (swine manure; poultry manure; compost; turkey manure; humus); $37.5 \mathrm{~kg} / \mathrm{ha}$ of $\mathrm{N}$ (swine manure half dose); control (NPK, 30-120-60 kg/ha of $\mathrm{N}-\mathrm{P}_{2} \mathrm{O}_{5}-\mathrm{K}_{2} \mathrm{O}$ ) and double rate of NPK (60-240-120 kg/ha of $\left.\mathrm{N}-\mathrm{P}_{2} \mathrm{O}_{5}-\mathrm{K}_{2} \mathrm{O}\right)$; and unfertilized control. In mineral fertilization experiment, the mineral levels were 1 and 3 times the recommended rates based on soil analysis: $30-120-60 \mathrm{~kg} /$ ha of N-P $\mathrm{O}_{5}-\mathrm{k}_{2} \mathrm{O} ; 90-360-180 \mathrm{~kg} / \mathrm{ha}$ of $\mathrm{N}-\mathrm{P}_{2} \mathrm{O}_{5}-\mathrm{K}_{2} \mathrm{O} ; 75.0 \mathrm{~kg} / \mathrm{ha}$ of $\mathrm{N} ; 225.0 \mathrm{~kg} / \mathrm{ha}$ of N; $80.0 \mathrm{~kg} / \mathrm{ha}$ of $\mathrm{P}_{2} \mathrm{O}_{5} ; 240.0 \mathrm{~kg} / \mathrm{ha}$ of $\mathrm{P}_{2} \mathrm{O}_{5} ; 60.0$ $\mathrm{kg} / \mathrm{ha}$ of $\mathrm{K}_{2} 0 ; 180.0 \mathrm{~kg} / \mathrm{ha}$ of $\mathrm{K}_{2} 0$. Control plots with organic fertilization received swine manure + phosphate rock in three treatments $\left(75.0 \mathrm{~kg} / \mathrm{ha}\right.$ of $\mathrm{N}+80.0 \mathrm{~kg} / \mathrm{ha}$ of $\mathrm{P}_{2} \mathrm{O}_{5} ; 225.0 \mathrm{~kg} / \mathrm{ha}$ of N $+240.0 \mathrm{~kg} / \mathrm{ha}$ of $\mathrm{P}_{2} \mathrm{O}_{5} ; 37.5 \mathrm{~kg} / \mathrm{ha}$ of $\mathrm{N}+40.0 \mathrm{~kg} / \mathrm{ha}$ of $\mathrm{P}_{2} \mathrm{O}_{5}$ ) and unfertilized check. Downy mildew incidence was similar between treatments with fertilizer and no fertilizer check. Mineral fertilization did not increase downy mildew incidence compared to the organic treatments. The relationship between nutrient and disease varied according to sampling date and differed for mineral and organic sources.
\end{abstract}

Keywords: Allium cepa, Peronospora destructor, nutrient, organic agriculture, agroecology.

\section{(Recebido para publicação em 2 de novembro de 2003 e aceito em 30 de maio de 2004)}

$\mathrm{O}$ míldio, causado pelo oomyceto Peronospora destructor (Berk.) Casp. constitui-se em uma das principais doenças da cultura da cebola no Sul do Brasil, com altos riscos de perdas tanto na fase de canteiro como na lavoura, em pós-transplante (Boff, 1996). A ocorrência do míldio é correlacionada com condições climáticas de temperaturas amenas e alta umidade relativa do ar. Entretanto, relatos freqüentes por técnicos e agricultores na região do Alto Vale do Itajaí apontam para uma possível influência das condições de fertilidade dos solos, principalmente pelo excesso de adubações com NPK (dados não publicados).

O tipo de fertilização influencia a ocorrência de pragas e doenças em vá- rias plantas cultivadas (Patriquin et al., 1993; Zambolim e Ventura, 1993). Os nutrientes minerais podem aumentar ou diminuir a resistência das plantas aos patógenos, mas generalizar o efeito é impossível (Zambolim e Ventura, 1993). $\mathrm{O}$ efeito positivo do excesso de adubação (principalmente nitrogenada) sobre doenças em olerícolas é relatado por alguns autores. $\mathrm{O}$ nitrogênio em níveis altos resulta na produção de tecido jovem e suculento, pode também prolongar o estádio vegetativo e/ou retardar a maturidade da planta e favorecer a incidência de patógenos (Zambolim e Ventura, 1993). A incidência de antracnose, Colletotrichum spp., foi correlacionada positivamente com aumento das doses de $\mathrm{N}$ em frutos de pimenta, Capsicum spp. e de P nas folhas e frutos (Vos e Frinking,1997).

O uso de compostos orgânicos é prática viável para o manejo de patógenos (Pereira et al., 1996a). Além do efeito benéfico sobre as características físicoquímicas do solo, os compostos orgânicos atuam sobre as populações de patógenos e antagonistas e contribuem para induzir supressividade ao solo (Hoitink e Bohem, 1991 citados por Pereira et al., 1996a). O uso de composto orgânico de restos culturais de milho, feijão, arroz, café, capim associados com esterco animal reduziu o número de pústulas de ferrugem, Puccinia allii Rudolph, em alho, comparado à adubação mineral com a fórmula N-P$\mathrm{K}(4-14-8)+\mathrm{B}+\mathrm{Zn}+\mathrm{Mg}$ (Pereira et 
al., 1987). O uso de composto de lixo urbano na adubação de pepino não reduziu a incidência de fusariose, Fusarium oxysporum f. sp. cucumerinum, mas favoreceu a germinação e o desenvolvimento das plantas (Melloni et al., 1995). Pereira et al. (1996b) observaram que os compostos de lixo urbano, de casca de café e vermicomposto, reduziram a severidade e o progresso de mancha zonada (Leandria mormodicae) do pepino. Estes autores sugeriram que o mecanismo de controle foi a indução de resistência. Boff et al. (2000) observaram menor incidência da queima-acinzentada (Botrytis squamosa) da cebola em canteiros adubados por composto de descarte de cebola, esterco de suíno e capim elefante em comparação com adubos mineral e organo-mineral. Para que ocorra o efeito benéfico do composto orgânico na supressão de patógenos é necessário que o composto esteja estabilizado, ou seja com relação C:N entre 14:1 a 20:1 (Hoitink e Bohem, 1991, citados por Pereira et al., 1996a) e a umidade deve estar acima de $40 \%$ (v/v), sendo o ideal 65\% (v/v) (Pereira et al., 1996a).

A influência de $\mathrm{P}$ e $\mathrm{K}$ e da fórmula NPK é citada por alguns autores sobre a incidência de patógenos. Gupta e Singh (1995) observaram que aplicação de potássio, isoladamente, aumentou a incidência de míldio, Sclerospora graminicola (Sacc.) Schrot., em milheto, em comparação com aplicação de NPK. Os autores atribuíram este efeito ao excesso de potássio, pois este nutriente já estava em nível suficiente no solo. Reuveni et al. (1993) observaram redução da severidade do oídio (Uncinula necator (Schw.) Burr) em videira e aumento na produtividade e no número de cachos com altos níveis de NPK via fertirrigação. Os autores atribuíram o efeito principalmente ao fósforo, o qual teria incrementado nível de resistência ao patógeno. Develash e Sugha (1997) observaram que a severidade de míldio da cebola correlacionouse com incremento do nível de fósforo e de nitrogênio; enquanto o aumento dos níveis de potássio retardou o desenvolvimento da doença.

O estado de Santa Catarina tem na agricultura familiar a sua estrutura fundiária básica. A Epagri (Empresa de

Tabela 1. Níveis de nutrientes em diferentes fontes orgânicas de adubação. Ituporanga (SC) Epagri, 1998.

\begin{tabular}{lrrrrr}
\hline \multirow{2}{*}{ Nutriente } & \multicolumn{5}{c}{ Fonte de adubo orgânico } \\
\cline { 2 - 6 } & suíno & $\begin{array}{l}\text { Barriga } \\
\text { Verdeâ }\end{array}$ & composto & húmus & perú \\
\hline${ }^{*} \mathrm{MS}$ & 27,30 & 93,97 & 36,40 & 61,22 & 79,80 \\
$\mathrm{~N}$ & 34,90 & 26,50 & 20,30 & 37,60 & 29,40 \\
$\mathrm{P}$ & 23,60 & 15,80 & 14,70 & 26,60 & 20,80 \\
$\mathrm{~K}$ & 1,80 & 15,0 & 3,40 & 7,20 & 25,40 \\
$\mathrm{Ca}$ & 52,80 & 64,60 & 29,00 & 58,00 & 31,00 \\
$\mathrm{Mg}$ & 4,20 & 15,60 & 5,00 & 6,40 & 8,20 \\
$\mathrm{Fe}$ & 3822,00 & 10740,0 & 8686,0 & 6008,00 & 7230,0 \\
$\mathrm{Mn}$ & 368,00 & 636,00 & 318,00 & 634,00 & 574,00 \\
$\mathrm{Zn}$ & 650,00 & 298,00 & 244,00 & 990,00 & 468,00 \\
$\mathrm{Cu}$ & 596,00 & 108,00 & 232,00 & 734,00 & 112,00 \\
$\mathrm{~B}$ & 31,00 & 53,00 & 34,00 & 42,00 & 58,00 \\
\hline
\end{tabular}

*MS = matéria seca do adubo em porcentagem. Os macronutrientes foram expressos em g/ $\mathrm{kg}$ de MS do adubo, e os micronutrientes em $\mathrm{mg} / \mathrm{kg}(\mathrm{ppm})$ de MS do adubo.

Pesquisa Agropecuária e Extensão Rural de Santa Catarina) tem fomentado o desenvolvimento de sistemas de produção em base ecológica para que a agricultura familiar catarinense possa desenvolver-se de modo sustentável. A geração de informação com base científica que contribua para este processo é demanda crescente, como por exemplo a importância dos diversos oligoelementos na fisiologia da planta e a sua influência na resistência a insetos e patógenos.

O objetivo deste trabalho foi avaliar o efeito das adubações mineral e orgânica na ocorrência de míldio na cultura da cebola.

\section{MATERIAL E MÉTODOS}

Os experimentos foram conduzidos na Estação Experimental de Ituporanga, Epagri, em solo classificado como Cambissolo Húmico distrófico álico. A intensidade do míldio foi estudada no experimento 1 sob a influência de adubos orgânicos e no experimento 2 estudou-se o efeito de adubos minerais. A cultivar de cebola utilizada nos experimentos foi a Crioula e o delineamento experimental foi de blocos ao acaso com quatro repetições. $\mathrm{O}$ tamanho de parcela foi de 2,8 m x 3,0 m, compreendendo 210 plantas de cebola transplantadas no espaçamento de $40 \mathrm{~cm}$, entre linhas, e $10 \mathrm{~cm}$, entre plantas. As parcelas foram distanciadas de $1 \mathrm{~m}$, entre si, para efei- to de isolamento. O preparo do solo para o transplante foi realizado com auxílio de microtrator, cujos implementos foram adaptados ao transplante direto, em palhada. A palhada de cobertura do solo foi de centeio, semeado no mês de maio. O controle de invasoras foi realizado até a primeira semana de novembro.

A incidência do míldio foi avaliada pela contagem semanal do número de folhas infectadas e do número total de folhas em 1 metro linear por parcela, escolhido ao acaso, expressando-se o resultado em porcentagem de folhas doentes. A análise do teor de nutrientes nas folhas foi realizada em amostras de cinco plantas por parcela no laboratório da EE de Caçador, Epagri (SC).

Incidência de míldio em cebola sob diferentes fontes de adubação orgânica

Foi conduzido de 28/08/98 (transplante) a 16/12/98 (colheita), totalizando um ciclo de 110 dias. Os tratamentos foram 1) 15,7 t/ha de esterco de suínos; 2) 7,9 t/ha de esterco de suínos (metade da dose recomendada pela análise de solo); 3) 6,0 t/ha de esterco Barriga Verde ${ }^{\circledR}$ (aves); 4) 20,3 t/ha de composto orgânico; 5) 6,4 t/ha de esterco de peru; 6) $6,5 \mathrm{t} / \mathrm{ha}$ de húmus; 7) $0,6 \mathrm{t} / \mathrm{ha}$ de NPK 5-20-10; 8) 1,2 t/ha de NPK 5$20-10$; 9) testemunha sem adubação. Os tratamentos com fontes orgânicas forneceram o equivalente a $75 \mathrm{~kg} / \mathrm{ha}$ de $\mathrm{N}$, exceto o tratamento 2 , que correspondeu à metade da dose. Os tratamentos 7 e 8 
Tabela 2. Porcentagem de folhas infectadas com míldio, Peronospora destructor, e valores médios da área abaixo da curva de progresso da doença (AACPD) em cebola cultivar Crioula, sob adubações mineral e orgânica. Ituporanga (SC), Epagri,1998.

\begin{tabular}{|c|c|c|c|c|c|c|c|c|c|c|}
\hline \multirow{2}{*}{ Tratamento } & \multirow{2}{*}{$\begin{array}{c}\text { Doses de } \\
\text { nutrientes } \\
\text { (kg/ha) }\end{array}$} & \multicolumn{8}{|c|}{ Datas de avaliação } & \multirow{2}{*}{ AACPD } \\
\hline & & $14 / 10$ & $21 / 10$ & $28 / 10$ & $04 / 11$ & $11 / 11$ & $19 / 11$ & $25 / 11$ & $02 / 12$ & \\
\hline N (esterco de suíno) & 75,0 & 0,0 & 0,0 & 0,0 & 0,8 & 0,0 & 8,6 & 0,0 & 4,4 & $80,8 \mathrm{a}$ \\
\hline N (esterco de suíno) & 37,5 & 0,0 & 0,9 & 1,2 & 0,7 & 1,6 & 7,3 & 0,0 & 5,8 & $102,4 \mathrm{a}$ \\
\hline N (esterco Barriga Verde, â aves) & 75,0 & 0,0 & 0,0 & 0,9 & 0,0 & 5,0 & 16,4 & 0,0 & 9,8 & $192,9 \mathrm{a}$ \\
\hline N (composto orgânico) & 75,0 & 0,0 & 0,0 & 0,4 & 0,0 & 0,6 & 5,3 & 0,0 & 9,1 & $76,0 \mathrm{a}$ \\
\hline N (esterco de perú) & 75,0 & 0,0 & 0,5 & 0,9 & 0,6 & 1,5 & 10,9 & 0,0 & 13,0 & $147,4 \mathrm{a}$ \\
\hline N (húmus) & 75,0 & 0,0 & 3,4 & 0,4 & 1,2 & 1,6 & 11,1 & 0,0 & 8,6 & $154,7 \mathrm{a}$ \\
\hline N P K (5-20-10) & $30-120-60$ & 0,5 & 0,0 & 0,0 & 0,4 & 0,3 & 8,4 & 0,0 & 7,5 & 91,8 a \\
\hline N P K (5-20-10) & $60-240-120$ & 0,0 & 0,0 & 0,7 & 0,8 & 1,3 & 9,6 & 0,0 & 6,3 & $108,8 \mathrm{a}$ \\
\hline testemunha sem adubação & & 0,0 & 0,9 & 0,4 & 0,8 & 2,3 & 7,1 & 0,0 & 6,7 & $104,6 \mathrm{a}$ \\
\hline C.V.\% & & & & & & & & & & 43,9 \\
\hline
\end{tabular}

Médias seguidas da mesma letra na vertical não diferem entre si pelo teste de Tukey $(\mathrm{P} \leq 0,05)$.

corresponderam ao fornecimento de NPK uma e duas vezes, respectivamente, ao recomendado para a cultura, de acordo com a análise de solo. A determinação da quantidade de adubo orgânico utilizado foi baseada na análise do solo e na necessidade de nitrogênio para a cultura, segundo as recomendações da Comissão de Fertilidade do Solo RS e SC (1994). A dosagem de esterco foi calculada pela fórmula: quantidade de esterco/ha $=(100000 \times \mathrm{N}) /(\mathrm{MS} \times \mathrm{NMS}$ $\mathrm{x} 0,5)$, em que $\mathrm{N}$ é a quantidade de nitrogênio, em kg/ha, necessário para a cultura da cebola; MS é o teor de matéria seca do esterco em porcentagem; NMS é a quantidade de nitrogênio por $\mathrm{kg}$ de matéria seca do esterco; e 0,5 é o índice de liberação de nitrogênio pelo esterco, cerca de $50 \%$ no primeiro ano de aplicação. A análise de nutrientes nos adubos orgânicos foi realizada pelo laboratório da Estação Experimental de Caçador (Tabela 1).

O composto orgânico foi proveniente de resíduos culturais de cebola, esterco de suínos, capim cameroon (Pennisetum clandestinum Hochst. ex. Chiov.), e o húmus do esterco de suínos. Os adubos orgânicos foram distribuídos manualmente sobre a superfície do solo, enquanto as fontes de adubação mineral foram incorporadas com microtrator adaptado para plantio direto. As datas de avaliação da incidência do míldio foram 14/10 (47 dias após transplante = DAT), 21/10 (54 DAT), 28/ 10 (61 DAT), 04/11 (68 DAT), 11/11 (75 DAT), 19/11 (83 DAT), 25/11 (89 DAT) e 02/12/1998 (96 DAT).
Incidência de míldio em cebola sob diferentes fontes minerais de adubação

$\mathrm{O}$ experimento foi conduzido entre 01/09/98 (transplante) e 16/12/98 (colheita), perfazendo um ciclo de 106 dias. Consistiu de 12 tratamentos, sendo oito níveis de nutrientes fornecidos por adubação mineral, três referentes a dosagens de esterco de suínos associado ao fosfato natural e um tratamento sem adubação. A quantidade de adubo nos tratamentos com menores dosagens foi determinada considerando a análise do solo e em consonância ao recomendado para a cultura da cebola pela Comissão de Fertilidade do Solo RS/SC (1994). Nos tratamentos com maior dosagem, utilizouse três vezes o valor recomendado. Os tratamentos foram 1) $30-120-60 \mathrm{~kg} / \mathrm{ha}$ de N-P $\mathrm{O}_{5}-\mathrm{K}_{2} \mathrm{O}(0,6$ t/ha de NPK 5-2010); 2) 90-360-180 kg/ha de N-P $\mathrm{O}_{5}$ $\mathrm{K}_{2} \mathrm{O}(1,8 \mathrm{t} / \mathrm{ha}$ de NPK 5-20-10); 3$) 75$ $\mathrm{kg} / \mathrm{ha}$ de N (170,5 kg/ha de uréia); 4) $225 \mathrm{~kg} / \mathrm{ha}$ de $\mathrm{N}(511,5 \mathrm{~kg} / \mathrm{ha}$ de uréia); 5) $80 \mathrm{~kg} / \mathrm{ha}$ de $\mathrm{P}_{2} \mathrm{O}_{5}(195,1 \mathrm{~kg} / \mathrm{ha}$ de superfosfato triplo); 6) $240 \mathrm{~kg} / \mathrm{ha}$ de $\mathrm{P}_{2} \mathrm{O}_{5}(585,3 \mathrm{~kg} / \mathrm{ha}$ de superfosfato triplo); 7) $60 \mathrm{~kg} / \mathrm{ha}$ de $\mathrm{K}_{2} \mathrm{O}(103,4 \mathrm{~kg} / \mathrm{ha}$ de cloreto de potássio); 8) $180 \mathrm{~kg} / \mathrm{ha}$ de $\mathrm{K}_{2} \mathrm{O}(310,2 \mathrm{~kg} / \mathrm{ha}$ de cloreto de potássio); 9) $75 \mathrm{~kg} / \mathrm{ha}$ de $\mathrm{N}+80 \mathrm{~kg} / \mathrm{ha}$ de $\mathrm{P}_{2} \mathrm{O}_{5}(15,7 \mathrm{t} / \mathrm{ha}$ de esterco de suínos + $0,2 \mathrm{t} / \mathrm{ha}$ de fosfato natural); 10) $225 \mathrm{~kg} /$ ha de $\mathrm{N}+240 \mathrm{~kg} /$ ha de $\mathrm{P}_{2} \mathrm{O}_{5}(47,2 \mathrm{t} / \mathrm{ha}$ de esterco de suínos $+0,6 \mathrm{t} / \mathrm{ha}$ de fosfato natural); 11) $37,5 \mathrm{~kg} / \mathrm{ha}$ de $\mathrm{N}+40 \mathrm{~kg} /$ ha de $\mathrm{P}_{2} \mathrm{O}_{5}(7,9 \mathrm{t} /$ ha de esterco de suínos $+0,1 \mathrm{t} / \mathrm{ha}$ de fosfato natural); 12) testemunha sem adubação. $\mathrm{O}$ fosfato natural utilizado foi GAFSA® com $\mathrm{P}_{2} \mathrm{O}_{5}$ total de $28 \%$, sendo $9 \%$ solúvel em ácido cítrico e o teor de Ca igual a $34 \%$.

As datas de avaliação da incidência de míldio com respectivos dias após transplante (DAT), foram: 15/10 (44 DAT), 22/10 (51 DAT), 29/10 (58 DAT), 05/11 (65 DAT), 12/11 (72 DAT), 20/11 (80 DAT), 26/11 (86 DAT) e 03/12/1998 (93 DAT). As coletas para análise foliar foram realizadas em: 15/10 (44 DAT), 12/11 (72 DAT) e 03/12/1998 (93 DAT).

Os valores de variáveis climáticas durante a avaliação dos dois experimentos foram similares: temperaturas mínima de $15,2^{\circ} \mathrm{C}$, média de $19,5^{\circ} \mathrm{C}$ e umidade relativa de $78 \%$. A insolação acumulada foi de 240,6 e 241,7 h e a precipitação acumulada foi de 125,1 e 138,9 $\mathrm{mm}$, para os experimentos 1 e 2 , respectivamente.

Os dados de incidência de míldio foram utilizados para calcular a área abaixo da curva de progresso da doença (AACPD), segundo Shaner e Finney (1977). As médias foram comparadas pelo teste de Tukey $(\mathrm{P} \leq 0,05)$. A análise com regressão múltipla ("proceeding stepwise do programa estatítico SAS $®$ foi aplicada na estimativa da relação entre a incidência de míldio e os níveis foliares de nutrientes.

\section{RESULTADOS E DISCUSSÃO}

A área abaixo da curva de progresso de míldio não diferiu para tratamentos com adubação em relação à testemunha em ambos experimentos (Tabelas 2 e 3 ). Estes resultados contrastam com 
Tabela 3. Porcentagem de folhas infectadas com míldio, Peronospora destructor, e valores médios da área abaixo da curva de progresso da doença (AACPD), em cebola cultivar "Crioula", sob adubações mineral e orgânica. Ituporanga (SC), Epagri,1998.

\begin{tabular}{|c|c|c|c|c|c|c|c|c|c|c|}
\hline \multirow{2}{*}{ Tratamento } & \multirow{2}{*}{$\begin{array}{c}\text { Doses de } \\
\text { nutrientes } \\
\text { (kg/ha) }\end{array}$} & \multicolumn{8}{|c|}{ Datas de avaliação } & \multirow{2}{*}{ AACPD } \\
\hline & & $15 / 10$ & $22 / 10$ & $29 / 10$ & $05 / 11$ & $12 / 11$ & $20 / 11$ & $26 / 11$ & $03 / 12$ & \\
\hline NPK (5-20-10) & $30-120-60$ & 0,5 & 2,6 & 2,0 & 1,7 & 22,9 & 13,8 & 4,6 & 9,8 & $377,6 \mathrm{a}$ \\
\hline NPK (5-20-10) & $90-360-180$ & 0,5 & 5,3 & 6,9 & 5,0 & 36,3 & 10,5 & 11,6 & 10,0 & $578,0 \mathrm{a}$ \\
\hline N (uréia) & 75,0 & 0,6 & 4,1 & 1,3 & 3,7 & 13,6 & 14,9 & 6,2 & 22,6 & $390,6 \mathrm{a}$ \\
\hline$N$ (uréia) & 225,0 & 0,0 & 3,0 & 3,0 & 2,0 & 21,4 & 17,1 & 4,2 & 17,3 & $422,6 \mathrm{a}$ \\
\hline P2 O5 (super triplo) & 80,0 & 0,0 & 3,3 & 2,0 & 3,3 & 19,9 & 6,4 & 6,1 & 10,2 & $328,9 \mathrm{a}$ \\
\hline P2 O5 (super triplo) & 240,0 & 1,4 & 0,9 & 0,9 & 0,9 & 14,7 & 6,8 & 8,3 & 21,4 & $310,3 \mathrm{a}$ \\
\hline K2 0 (cloreto de potássio) & 60,0 & 1,1 & 2,3 & 3,7 & 3,6 & 27,2 & 13,0 & 15,1 & 18,6 & $528,6 \mathrm{a}$ \\
\hline K2 0 (cloreto de potássio) & 180,0 & 0,9 & 2,3 & 1,5 & 2,2 & 14,2 & 10,1 & 8,6 & 20,4 & $348,9 \mathrm{a}$ \\
\hline $\begin{array}{l}\mathrm{N}+\mathrm{P} \text { (esterco de suíno + } \\
\text { fosfato natural) }\end{array}$ & $75,0+80,0$ & 0,5 & 2,4 & 1,3 & 3,8 & 19,9 & 14,3 & 18,6 & 21,1 & $497,0 \mathrm{a}$ \\
\hline $\begin{array}{l}\mathrm{N}+\mathrm{P} \text { (esterco de suíno + } \\
\text { fosfato natural) }\end{array}$ & $225,0+240,0$ & 1,6 & 2,6 & 2,7 & 3,4 & 30,1 & 10,9 & 15,0 & 5,6 & $485,0 \mathrm{a}$ \\
\hline $\begin{array}{l}N+P \text { (esterco de suíno + } \\
\text { fosfato natural) }\end{array}$ & $37,5+40,0$ & 0,0 & 2,8 & 2,7 & 7,0 & 18,9 & 11,6 & 10,0 & 18,2 & $439,1 \mathrm{a}$ \\
\hline testemunha sem adubação & & 0,0 & 1,4 & 2,4 & 3,0 & 23,1 & 9,9 & 5,7 & 13,6 & $375,2 \mathrm{a}$ \\
\hline C.V. (\%) & & & & & & & & & & 30,9 \\
\hline
\end{tabular}

Médias seguidas da mesma letra na vertical não diferem entre si pelo teste de Tukey $(\mathrm{P} \leq 0,05)$.

Mcguire (1999), que observou menor incidência de míldio em cebola sob adubação orgânica comparado a mineral. A constatação de Boff et al. (2000) do efeito supressivo de composto sobre a incidência de queima acinzentada em canteiro de cebola também não foi observada para míldio. Provavelmente, pela ocorrência de míldio ser normal no póstransplante, o que não permite colocar altas dosagens de composto que pudessem provocar tal efeito, o que é facilitado em canteiro pela menor área. Não foi constatada tendência do incremento da incidência de míldio por adição de adubação com N, bem como a redução por K, como observado por Huber (1991) e Huber e Arny (1985) citados por Huber (1994). Porém, como ressaltado por Huber (1991) e Huber e Watson (1970) citados por Huber (1994), isto ocorre com o $\mathrm{N}$ na forma nítrica, que é prontamente disponível nos tecidos foliares, onde ocorre a infestação de parasitas obrigatórios, enquanto que o $\mathrm{N}$ na forma amoniacal é primariamente metabolizado nas raízes. Este autor levantou a possibilidade de que a forma de $\mathrm{N}$ amoniacal embora promova crescimento foliar favorece também a entrada de manganês, que atua no processo de lignificação da planta e inibe a atividade de enzimas produzidas pelo fungo para decompor o tecido foliar. A ati- vidade inibitória de Mn no tecido foliar sobre a ocorrência de doenças fúngicas em cebola como observado por Huber (1994) não ocorreu, o que sugere haver a necessidade de suplementação deste nutriente via adubação para que isto ocorra. O efeito de fontes orgânicas de adubação como indutores de resistência ao patógeno não foi significativo comparado a adubação mineral como observado por Melloni et al. (1995) e Raviv et al. (1998). Provavelmente, os níveis de nutrientes fornecidos pelas diferentes fontes de adubação não foram capazes de alterar o estado nutricional das plantas e favorecer a incidência de míldio. Adicionalmente, o sistema de plantio direto adotado no experimento pode ter proporcionado uma relação solo-planta-patógeno similar entre diferentes tratamentos.

A análise de regressão múltipla entre nutrientes e incidência de míldio no experimento com fontes orgânicas apresentou as seguintes equações, com os valores significativos $(P \leq 0,05)$ : para data 11/11 com nível de infestação máximo de $5 \%, y=-2,56+9,10 x \mathrm{P} / \mathrm{Ca}$ $\left(r^{2}=7,77 \%\right)$; para data $02 / 12$ com o mais alto nível de infestação da doença (13\%, Tabela 2), $y=-3,48+3,7 x M g-0,86 x F e /$ $\mathrm{Zn}+0,49 \mathrm{xFe} / \mathrm{Mn}\left(\mathrm{r}^{2}=42,3 \%\right)$. A análise de regressão múltipla para incidência de míldio e sua relação com nutrien- tes no experimento com fontes minerais apresentou as seguintes equações: no início da infestação da doença não houve relação significativa (em 15/10, Tabela 3); no maior nível de incidência da doença na testemunha (em 12/11) com valores significativos $(P \leq 0,05)$, $\mathrm{y}=-36,16-0,16 \mathrm{xMg} / \mathrm{B}+0,26 \mathrm{xP} / \mathrm{Fe}$ $\left(\mathrm{r}^{2}=16,35 \%\right)$; próxima à maturação fisiológica com nível de incidência de míldio entre $5,6 \%$ a 22,6\% (em 03/12), $\mathrm{y}=-20,80-0,02 \times \mathrm{P} / \mathrm{Cu}\left(\mathrm{r}^{2}=8,97 \%\right)$. Convém ressaltar que o tempo mais lento na disponibilidade de nutrientes para fontes orgânicas de adubação em relação à mineral, associado ao histórico de manejo da área experimental, também orgânico, poderia ter favorecido a relação significativa entre nutriente $\mathrm{e}$ patógeno apenas no final do ciclo da cultura. Os valores de coeficientes de determinação $\left(r^{2}\right)$ entre nutrientes e incidência de míldio foram geralmente baixos em ambos experimentos. Os níveis obtidos pelo coeficiente de determinação entre níveis foliares de nutrientes e míldio embora significativos foram inferiores a $42,3 \%$, o que indica que não houve relação entre nutrição e doença. Portanto, a relação entre nutrientes e míldio geralmente não foi linear. A relação não linear entre nitrogênio e doença já havia sido constatada anteriormente por Broscious et al. (1985). A inci- 
dência de míldio não foi correlacionada com o incremento de $\mathrm{P}$ e $\mathrm{N}$ de maneira isolada, como observaram Develash e Sugha (1997). Convém considerar, que os níveis de nutrientes fornecidos não causaram desequilíbrio nutricional suficiente que pudesse interferir na incidência do patógeno (Tabelas 2 e 3).

\section{AGRADECIMENTOS}

À Embrapa, pela concessão de bolsa de estudo no período de realização do trabalho. Ao pesquisador Dr. Odo M.A.S.P.R. Primavesi (Embrapa, CPPSE, São Carlos, SP), pelas sugestões apresentadas. À pesquisadora Dra. Márcia Mondardo Spengler (Epagri, EE de Caçador), pelos esclarecimentos nas análises estatísticas. Ao técnico agrícola Marcelo Pitz (Epagri, EE Ituporanga, $\mathrm{SC}$ ) e sua equipe, pelo apoio na condução do trabalho.

\section{LITERATURA CITADA}

BOFF, P.; DEBARBA, J.F.; SILVA E.; WERNER $\mathrm{H}$. Increasing onion plant health by thermophilic compost. In: ALFÖLDI, T.; LOCKERETZ, W.; NIGGI, U. (Eds.). PROCEEDINGS INTERNATIONAL IFOAM SCIENTIFIC CONFERENCE, 13., 2000, Basel. Proceedings... Zürich: IFOAM, p.56.

BOFF, P. Levantamento de doenças na cultura da cebola, em Santa Catarina. Fitopatologia Brasileira, Brasília, v.21, n.1, p.110-114, 1996.
BROSCIOUS, S.C.; FRANK, J.A.; FREDERICK, J.R. Influence of winter, wheat management practices on the severity of powdery mildew and septoria blotch in Pennsylvania. Phytopathology, v.75, n.5, p.538-542, 1985.

COMISSÃO DE FERTILIDADE DO SOLO RS/SC. Recomendações de adubação e de calagem para os estados do Rio Grande do Sul e de Santa Catarina. 3 ed. Passo Fundo: SBCS Núcleo Regional Sul, 1994. 224 p.

DEVELASH, R.K.; SUGHA, S.K. Factors affecting development of downy mildew (Peronospora destructor) of onion (Allium cepa). Indian Journal of Agricultural Sciences, v.67, n.2, p.71-74, 1997.

GUPTA, G.K.; SINGH, D. Downy mildew control in pearl millet through nutrient application. Indian Phytopatology, v.48, n.4, p.439-443, 1995.

HUBER, D.M. The influence of mineral nutrition on vegetable diseases. Horticultura Brasileira, Brasília, v.12, n.2, p.206-214, 1994.

McGUIRE, M.E. Efeitos do manejo do solo sobre fisiologia vegetal e incidência de pragas $e$ doenças na cebola. Florianópolis: UFSC, 1999. 62 p. (Tese mestrado)

MELLONI, R.; DUARTE, K.M.R.; CARDOSO, E.J.B.N. Efeito do composto de lixo urbano e/ou de E.M.4 (effective microorganisms) no desenvolvimento de pepino (Cucumis sativus) e no controle de fusariose. Summa Phytopathologica, Piracicaba, v.21, n.1, p.21-24, 1995.

PATRIQUIN, D.G.; BAINES, D.; ABBOUD, A. Soil fertility effects on pests and diseases. In: COOK, H.F.; LEE, H.C. (Eds.). Proceedings of the Third International Conference on Sustainable Agriculture. London: Wye College Press, 1993. p.161-174.

PEREIRA, E.B.; FORNAZIER, M.J.; VENTURA, J.A.; CARMO, C.A.S.; SOUZA, J.L.; PREZOTTI, L.C.; DESSAUNE FILHO, N. Efeito do composto orgânico na produtividade do alho e reação a praga e patógenos. Cariacica, EMCAPA, 1987. 8 p. (EMCAPA. Comunicado Técnico, 48).
PEREIRA, J.C.R.; ZAMBOLIM, L.; VALE, F.X.R.; CHAVES, G.M. Compostos orgânicos no controle de doenças de plantas. In: LUZ, W.C.; FERNANDES, J.M.; PRESTES; A.M.; PICININI, E.C. (Eds.) Revisão Anual de Patologia de Plantas. Passo Fundo: RAPP, 1996a. v.4, p.353-379. PEREIRA, J.C.R.; SILVA-ACUÑA, R.; GUIMARÃES, F.B.; CHAVES, G.M.; ZAMBOLIM, L. Novos enfoques no controle da mancha zonada (Leandria mormodicae Rangel) do pepino (Cucumis sativus). Fitopatologia Brasileira, Brasília, v.21, p.94-98, 1996b.

RAVIV, M.; KRASNOVSKY, A.; MEDINA S.; REUVENI, R.; FREIMAN, L.; BAR, A. Compost as a controlling agent against Fusarium wilt of sweet basil. Acta Horticulturae, v.469, p.375-381, 1998.

REUVENI, M.; NAOR, A.; REUVENI, R.; SHIMONI, M.; BRAVDO, B. The influence of NPK fertilization rates on susceptibility to powdery mildew of field-grown winegrapes. Journal of Small Fruit and Viticulture, v.2, n.1, p.31-41, 1993.

SHANER, G.; FINNEY, R.E. The effect of nitrogen fertilization on the expression of slowmildewing resistance in knox wheat. Phytopathology, v.67, n.10, p.1051-1056, 1977.

VOS, J.G.M.; FRINKING, H.D. Nitrogen fertilization as a component of integrated crop management of hot pepper (Capsicum spp.) under tropical lowland conditions. International Journal of Pest Management, v.43, n.1, p.1-10, 1997.

ZAMBOLIM, L.; VENTURA, J.A. Resistência a doenças induzida pela nutrição mineral das plantas. In: LUZ, W.C.; FERNANDES, J.M.; PRESTES; A.M.; PICININI, E.C. (Eds.) Revisão Anual de Patologia de Plantas. Passo Fundo: RAPP, 1993. v.1, p. 275-318. 